\title{
Collection development in digital libraries: trends and problems
}

\author{
R. Kavitha \\ Library, S.D.N.B. Vaishnav College for Women, Chennai-600 044, India \\ kavi_nivedha@yahoo.co.in
}

\begin{abstract}
This paper describes various trends in collection development in digital environment. The changes that have occurred in acquisition, retrieval and storage of information due to technological developments have been discussed. Limitations, restrictions and problems being faced by librarians and readers due to the same have also been discussed. The way these developments have affected the academic environment and changed the role of librarian has also been portrayed.
\end{abstract}

Keywords: Digital library, problem, archive, learning, India

\section{Introduction}

Libraries are the repositories of the wisdom of ages stored in the form of recorded information for use of present and future generations. Digital technology has made it more easy and comfortable to apply this wisdom and use the collected information for further research and overall development of the society. Earlier, the main task of the librarian was just the material selection but now the same has been extended to the creation and maintenance of web sites, teaching specific references, fund raising and other tasks. Even when libraries have been restructured and divisions have been given new names like computer application division etc., the work is still perceived as belonging either to technical services, reference service or acquisition. In fact, collection development is hybrid work incorporating both technical and public services. Positions that blur the lines among these organizational units are difficult to define and evaluate (Jakubs, 1999).

\section{Use of 'IT' in libraries}

The acquisition, processing, storage and dissemination of vocal, pictorial, textual, graphic and numeric information by a microelectronic based combination of computing and telecommunication is IT (Parekh, 2003). It is a combination of various technologies and its major components are computers, telecommunications and reprography. Use of IT in libraries can broadly be grouped into two main categories: Creation of information, knowledge and its dissemination and communication to the end user. Second aspect of it is related to the in-house processes and activities of libraries.

\section{Library collection and its importance}

Library collection has witnessed the ages of clay tablets to papyrus sheets, paper documents, and silicon chips, optical and magnetic disc and so on. In every age, libraries have used the latest technology. Importance of a library collection lies in the following functions, which it performs:

- Collection and dissemination of information is the most important function of a library;

- Importance and success of library collection lies in the satisfaction of user's information needs;

- Educational reading in a formal sense is the concern of academic, special and technical libraries. Such libraries should have such a varied collection so that they are able to fulfill these needs;

- In institutes of higher learning, provision of syllabi study and research material is another reason for library collection; and

- To make provision of information material for cultural and recreational reading is another important aspect, which enhances the importance of library collection. Collection preserves knowledge for the future;

Above all, library collection is the pool of achievements of the past preserved for the benefit of present and future generations. The scope of library collection shall be much clear from the classification of documents given in Annexure1.

The vast majority of digital documents with plenty of new attractive features as detailed below has brought about a revolution in our lives. The features of $21^{\text {st }}$ century information and media are (Satija, 2003):

- High compact storage;

- Ease of reproduction, multiplication and manipulation and transmutation;

- Contents can be very easily detached from its media or container;

- Ease of migration of contents from one medium to another;

- Ease of transmission, communication and storage;

- Hypertext and multimedia;

- Seamless integration of print and electronic resources;

- Sophisticated and multiprong searches through keywords, free text, Boolean operators, class numbers and natural languages processing;

- Wall less libraries leading to the vision of multimedia global virtual library (MGVL) inaugurating an era of "Death of distance"; and

- Convergence of technology, which is getting more powerful each day;

\section{Trends in electronic collection development}

The concept of what constitutes collection development has changed and perhaps we should look for a new definition of the role of a librarian. We have moved from a time of huge resources to a time of largely
Sci. Technol. Edu.

CIndian Society for Education and Environment (iSee)
"Digital library"

http://www.indjst.org 
static budgets with many more demands on these funds. This has shifted the focus of collection development from local collection building to more co-operative ventures and towards a heavier reliance on resource sharing (Jakubs, 1999). Main changes or the new trends, which have come on the forefront during the recent years, are detailed below:

\section{Move towards the use of approval plans}

To attain efficiency there has been a move towards the use of approval plans as a means of acquiring current publications. It has changed the job of a selector. Infact most approval plans require a great deal of monitoring from the initial profile design to regular reviews of materials. Approval plans have so many advantages also. Such as:

- The speed with which they bring new publications to the library without going through the order process; and

- Availability of latest information in the shortest possible time on the librarians table and researchers desktop without making any special effort in this direction. But approval plans alone cannot provide all the books needed in a library. They must be supplemented by confirm orders by librarian's knowledge about the collection and curricula (Jakubs, 1999);

\section{Replacement of complimentary copies of print} environment with trail access

In print environment, major publicity strategy of the publishers is providing complimentary copies to the teachers or libraries. This trend has changed in case of digital documents. In digital environment to publicize the products, publishers generally give trial or complimentary access for a particular period to the institutions. The same is generally activated on the institute servers to be accessible to all through the LAN. Decision for purchase is generally taken after watching the document during the trial period.

\section{Reduced acquisition}

Net decrease in funding has led to reduced acquisition and has also required more careful selection of materials. After all, it is easier to spend a large budget than a small one. This has further added to the job of librarians, as has the need in recent years to conduct a large-scale serial cancellation. Redirecting a very significant portion of serial budget towards electronic access paid on an annual basis is another dominating trend in libraries. Purchase of equipment to access the digital information is another additional liability on the libraries which has affected the quantity of acquisition in all libraries. In this regard it has been very rightly said that we, of course need money for legitimate purpose such as paying salaries $(80 \%$ of our budget), upgrading networking and computing capabilities, maintaining and modernizing aging physical facilities, and maintaining a traditionally acquisition oriented library while building the digital library for the future (Stoffle et al., 1999).

\section{Rigidity in acquisition process}

There is no doubt that information and communication technology (ICT) has brought many exciting and powerful new resources to our libraries but it also has negative effect on collections in support of disciplines that depend more on monographs. It has reduced the flexibility in our material budgets as a higher percentage of our budget is directed each year towards ongoing commitments or to continue the existing subscriptions.

Co- existence of two information systems: print and digital

The collection development and collection management embraces two information systems i.e. print and digital. In the libraries of some reputed institution like IITs, information and communication technology was adopted at an early stage and has adopted separate techniques suitable for development of both print and electronic collection. But in most of the Institutes, there are no clear-cut set of rules/ policies for development of both these medias. It is appropriate to recall the conclusion drawn by Satija and Sasikala (2005) that "the new technology is in no way in conflict with print document rather our so called hybrid libraries are the harmonious blend of tradition and modernity".

\section{Change in the role of librarian}

The very important role that emerges from our librarians is a redefinition of their role as information mediators. To make these role even more important, librarians need to add value to the information as it moves through this chain. The added value does not come from passively relaying the information we receive from the producers on to the consumers. The added value comes from insisting on quality products at reasonable prices and from value added by the library's own organizing, linking, and retrieval and access systems (Dillon, 1999).

Globalization of information with the establishment of institutional repositories

Establishment of institutional repositories in a number of internationally reputed institutions like IITs, IIMs, DRTC, and INSA etc. is another positive trend in the electronic collection development in India. Institutional repository is a contemporary concept that captures and makes available as much of the institutional research output as possible to the users. It is a sort of a database of digital information, resources, accessible through internet or intranet. In the first instance, this might include electronic version of documents such as research papers, project reports, patents, thesis, and dissertation. It may also include many of the digital assets generated by an institution such as working papers, lectures, conference proceedings, assignments, question papers, syllabus etc. In print environment, all the institutional research output remains limited to be used within the four walls of a library. But digital technology has led the globalization of such information. Some subject specialist institutional repositories are also there where scholars of a particular subject can contribute their documents on the subject.
Sci. Technol. Edu.

CIndian Society for Education and Environment (iSee)
"Digital library"

http://www.indjst.org
Kavitha

Indian J.Sci.Technol. 
Librarian's digital library (LDL) of DRTC, Bangalore is a subject specific repository that provides access to articles, conference papers, dissertations tutorials and other learning materials pertaining to library and information science. The submission of documents by the professionals of other institutions is also permissible in LDL (http://drtc.isbang.ac.in).

Blurring boundaries between different modes of delivering information

Collection boundaries are changing day-by-day. New boundaries, new structures for collection development are dominating the acquisition of reference tools, electronic journals and digital archives of historical materials in bundled packages. Many virtual communities of libraries have emerged after new opportunities for cooperative collection management. All these changes have powerful implications for the work of collection development librarians. But collection development work does not stop at these acquisition functions. It includes as well the follow up the selection decision, publicizing the collection, organizing it, assisting patrons in their use and expanding access to resources that may not even be held locally. So the librarians now have a range of functions that extend beyond what has generally been considered part of his/her job.

Increase in Interlibrary loan transactions

Use of interlibrary loan (ILL) is increasing, in many cases dramatically, probably because of cancelled journal subscriptions, the purchasing of fewer monographs, and the provision of online bibliographic databases. Improved service quality due to technological development could also be a factor. New technologies are transforming ILL, blurring the lines between ILL and document delivery services, and shifting costs.

\section{Coordinated and collaborative collection development}

There is no doubt that information has become the most important asset in today's fast and dynamic world, but still many readers do not have access to the diverse media of recorded information. It is also becoming almost impossible for any single library to preserve all type of materials and cater to all types of needs of its users/readers without resource sharing and online facilities. All libraries have limitations in terms of money, space and staff and the same can lead to the frustration of library users. So aspects like information explosion, literature scatter, rising prices, technological evolution and inelastic budgets are the major hurdles in the way of electronic collection development and hence have given rise to collaborative collection development (Vohra, 1999). Collaborative collection development in libraries opens up completely new opportunities to bridge the gap between big and small libraries. With the advancement of technology, more than one library's collection can be shared with their mutual cooperation and online facilities. Thus readers can approach the reading material of their interest not available in their own library. There are various ways to share library resources in a less costly manner but the most effective and cheapest way is the library consortium. INDEST/AICTE and UGC INFONET are the consortia which have taken ICT usage in India at par with the developed countries.

\section{Need for collaborative collection development}

Laxman Rao (2006) has appropriately depicted the need for consortia- "Library consortia have been formed to deal collectively with the problems of purchasing online products, to benefit from the best possible volume pricing, and to secure the best terms of agreement from online publishers".

Collaboration in library collection development is becoming indispensable medium to serve the needs of users with a view to:

- To avoid unnecessary duplication of materials;

- To acquire library materials purposively within the constraints of a limited budget;

- To facilitate accountability to external agencies;

- To develop specializations locally; and

- In response to the fragmented and uncoordinated acquisition of library materials the need for collaborative collection development is increasing day by day. In India one after the other consortia is taking place like INDEST consortia, UGC-Infonet. etc. UGC Infonet is a nationwide communication network of Indian academic Universities (http://web.inflibnet.ac.in/info/ugcinfonet.jsp).

\section{Outsourcing and electronic data interchange}

Outsourcing and Electronic Data Interchange (EDI) is gaining importance and has been suggested as a solution to shrinking financial and human resources by many experts in this field. In almost all libraries people are opting outsourcing for in-house activities of the libraries. Sipe (2006) has rightly termed the work flow of dealing with electronic resources as complex and stressed the need for experts to be hired through outsourcing.

\section{Challenges in electronic collection building}

The major challenges that we face today in this regard are:

\section{Complicated procurement and preservation system}

There are a very few reliable suppliers of digital documents in India. The lack of comprehensive and upto-date selection tools for digital documents further adds to the problems of a librarian. Foreign documents and far off markets are other problems in the way of electronic collection development. Even selective Digital archive will be massive. Who is to ensure that governments, organizations or publishers will maintain these archives for centuries in future? Hardware and software needed to preserve today's documents and use them decades later may not work. The hardware used to gain access to digital information changes radically and quite frequently. This means that preservation programmes must also involve considerations needed for access in future.
Sci. Technol. Edu.

CIndian Society for Education and Environment (iSee)
"Digital library" http://www.indjst.org 


\section{Technological obsolescence}

Periodical transfer of digital material from one hardware/software configuration to another or from one generation of computer technology to a subsequent generation is quite a common trend and a big challenge to e-collection development. The purpose of this migration is to preserve the integrity of digital objects and to retain the ability for clients to retrieve, display and otherwise use them in the face of constantly changing technology (Nagar, 2003). Obsolescence of equipments required to access digital information directly affects the longevity of digital information (Bhatt \& Singh, 2004). To ensure longer life of the digital information a continuous development and upgradation of information storage and access techniques and technology is a must.

Non compatibility of organizational culture to digital environment

Organizational cultures of most of the libraries due to their following features become a great hindrance in the way of e-collection development (Deoghuria, 2004).

- Non availability of full time highly skilled computer professional in libraries;

- Lack of coordination between computer professionals within and outside the organization;

- Lack of interest to keep track with the ever-changing information seeking behavior of library users;

- Lack of interest to add values to their services;

- Lack of interest to interact with users;

- Lack of interest to utilize physical space of the library; and

- In developing digital environment electricity/power plays a major role. We cannot think of digital library, which can work off efficiently without power for several hours. The other related problems like poor quality of telecommunication services, lack of technology standards, legal restrictions are also there.

\section{Financial constraints}

Cost involved in the creation and maintenance of digital library environment is quite high. In this context, financial restraints are much more severe in developing nations like India than the developed ones. Nowhere in the world are library budgets keeping pace with the growth of information, documents and ever-increasing demand for them. The budget allotted to most of the libraries, however remain static year after year. Even if there is no such cut, the purchasing power of the allotted money goes on dwindling due to inflation. Though the problem of shrinking budget is a universal one, it is quite serious in India on many counts.

\section{Resistance to change}

Traditional library science education with less emphasis on IT skills still continues in Indian universities. As a consequence of it, the library personnel in most of the libraries in India are happy with the existing routine procedures and services. In the recent years many libraries have hired computer professionals to handle the purchase and other issues related to digital documents.

This gives an assumption that computer professionals are taking precedence over the library professionals. It has happened so because many a time librarians have given responsibilities of selecting and handling electronic resources to computer professionals. Some complications are also there due to the advent of new resources. All these changes have happened quickly, and adapting to them is not always easy or comfortable. There are no opportunities for continuing professional education for the collection development methods. Gradual shift-over towards digital info high-tech from traditional rudimentary adherence has given rise to certain fears in the minds of the library professionals (Das, 2004). On the basis of our interaction with the librarians and other library professionals following conclusions have been drawn in this regard.

- Librarians in some organizations are happy with usual library routine services. Even during hands on training of online and library automation, most of the trainees are not susceptible to training opportunity of handling electronic devices;

- Shift to new technologies requires training; and training requires will-power, enthusiasm and confidence in ones capabilities. In the existing generation of librarians and other library professional who entered this profession before 1990s all these traits is either missing or not up to the degree the same are required to be present. Lack of clear set of skills for librarians also adds to the problems in the way of collection development. Majority of the institutions do not fully recognize the importance of IT skills for the librarians, and hence such posts are generally advertised with the knowledge of computer as desirable or additional qualification rather than making it mandatory;

- Various library and information schools in developing countries are still following traditional theoretical concepts, as a result library professionals are still lacking in skills, which are required for implementing the upcoming technologies in libraries;

- Some experts are of the opinion that there may be physical strain due to flare and glare of electronic operations;

- The jargonisation of information products and services falling within the sense of digital libraries have given rise to another kind of fear;

- The problems of ethical kind in terms of digital library operation, specially concerned to end users, are prevalent almost in every working environment; and

- The fear of fragility, safety, privacy, fraud and high cost against digital information services has gradually vanished at the stage of global competitiveness, precision technology and economy.

\section{Decentralization of library services}

With the digitization and automation of library services, a fear is there in the minds of library professionals that with the availability of information on the reader's desk importance of librarians may diminish.

Sci. Technol. Edu.

CIndian Society for Education and Environment (iSee)
"Digital library"

http://www.indjst.org
Kavitha

Indian J.Sci.Technol. 


\section{Access related problems}

There are many problems related to the nonavailability of the facility to download open access article. Sometimes, some special software is required to be installed before downloading some information from Web. This problem is generally there when some information is not available PDF format. Many types of digital divides such as divide between rich and poor, divide between developed and developing countries, linguistics and cultural divide, urban and rural, divide between young and old, etc are also a great hindrance in the development of collection of digital information.

\section{Security in library environment}

In view of the increasing number of attacks on computers with viruses, Trojan horses, spy wares, hackers etc., security in the library computer environment has become a great task and headache for librarians. Installation of antivirus software and regular updating of the same has become a pre-condition to information retrieval in digital environment. In the absence of the same the information stored in the hard disk of your PC has no permanence. The continuous attack of virus may damage or corrupt it at any time. Copyright issues are constant headache for possession and services of digital documents. Easy piracy adds fuel to the fire. The new digital environment has opened great concern all over the world towards Intellectual Property Rights (IPR) issues in general and copyrights in particular. GATT negotiations at Uruguay led to the conclusion of agreement on Trade Related Aspects of Intellectual Property Rights (TRIPS) which dealt with some of the copyright issues, including digital issues (Choudhary et al., 2004). These treaties have given some relief to the producers of digital information/authors at international level.

Absence of a national repository of digital documents and legislative provisions in this regard

There is no legislative provision to make it mandatory for publishers to deposit electronic and optical publication with a national center as it are available for print documents. To establish the reliability and authenticity of document such a provision is very much necessary. However, sometimes back a National Centre for digital publications was established at the Foundation for Innovation and Technology Transfer (FITT) at Indian Institute of Technology, Delhi. Based on the availability of resources the centre is concentrating on the following areas.

- Knowledge and information products; and

- Titles published on CD media;

The centre has adopted a mechanism for locating electronic publications. In the process of acquisition, the centre procures all the products costing up to Rs. $20,000.00$ after reviewing the contents by a committee. The centre compiles a union catalogue of CD titles held in Indian libraries. The members get a copy of union catalogue at free of cost. The website being set up exclusively for the centre helps the users to get a general description of Indian CD products. The national centre for digital publication is a milestone in the digital information collection in India.

Problems related to check the reliability and authenticity of digital information.

The vast majority of digital information is worthless, only of temporary usefulness, or of very local interest. It is truer of information on the web. How is all that information separated from the worthwhile one? Who will undertake the labour that it requires? Bernard William, in his book Truth and truthfulness observes that (William, 2002). "Accuracy and sincerity are important virtues in the transmission of an assertion. Our knowledge is continuously being modified by new information which in the absence of any contra-indication we assume to be correct. However from time to time we need or hear reports that contradict or disapprove previous impregnations. But which is right, what we knew or what we now learn? We are so used to information being presented in ways designed to influence us that we are skeptical of the facts themselves. It would not be too unfair to say that we live in a time when we wonder what we can trust. How much of the information we receive is reliable, in what circumstances and for how long?"

\section{Conclusion}

The concept of digital library in India has gained momentum with the launching of INDEST-Indian National Digital Library in Engineering Science and Technology, UGC-INFONET, SNDP-Sustainable Development Networking Programme of UNDP. Collection development of digital libraries is greatly influenced by a number of stakeholders such as library and information science professionals, publishers, subscription agencies, database manager and information services providers. The day is not far off to visualize all Indian libraries with huge digital collection and the latest technology to access the same. Digital resources are affecting collection development and management policies and are drawing attention to two areas that have been neglected for too long in Indian libraries, namely how do libraries change to meet the new searching habits of users on internet and how do collection managers react to changing information needs of users. With more and more resources available in digital format, the collection development has to include these resources, thus making them easily accessible to users. The policy should include these resources, thus making them easily accessible to users. The policy should include these resources enabling their selection, acquisition, preservation and distribution.

\section{References}

1. Bhatt RK and Singh K P (2004) Digital libraries: emergence features, challenges and opportunities. Tata Energy \& Res. Instt., New Delhi. pp: 49-55.

2. Choudhary Parvin Kumar, Bhattacharya Partha and Khan SD (2004) Concept of copyright in digital
Sci. Technol. Edu.

CIndian Society for Education and Environment (iSee)
"Digital library" http://www.indjst.org 
environment the legal issues in relation to WTO obligations and the doctrine and the doctrine of "Fair use". Tata Energy \& Res. Instt., New Delhi. pp:66-72.

3. Das Subarna (2004) Digital libraries in developing countries: fears and barriers. Tata Energy \& Res. Instt., New Delhi. pp: 997.

4. Deoghuria Swapan (2004) Are research libraries in India prepared in digital age? Tata Energy \& Res. Instt., New Delhi. pp: 76-80.

5. Dillon Dennis (1999) Making the wild wind visible: Information technology in a brave new world. Haworth Press, New York. pp: 47-61.

6. Jakubs Deborahs (1999) Staffing for collection development in electronic environment: Towards a new definition of roles and responsibilities. Haworth Press, New York. pp: 71.

7. Jakubs Deborahs (1999) Staffing for collection development in electronic environment: Towards a new definition of roles and responsibilities. J. Library Admin. 28(4), 71-83.

8. Laxman N. Rao (2006) Knowledge-sharing activities in India. Library Trends. 54(3), 463-484.

9. Nagar BR (2003) Digital library: Issues related with the digitization and sharing of resources. In: Electronic information environment and library services: A contemporary paradigm. $48^{\text {th }}$ ILA Conf. Papers, Bangalore, NIMHANS. Ed. Sharma \& Pandey SK, Indian Library Association, Delhi. pp:178-191.
10. Parekh Harsha (2003) IT and its impact on libraries. In: SHPT-School of Library Science Past Students Association, Bombay pp:143-158.

11. Satija MP ( 2003) Digital information systems and services. Laslic Bull. 48 (1), 10-13.

12. Satija MP (2005) Delivery of information services through distributed information environment: some stray thoughts and issues. Soc. for Information Sci., New Delhi. pp:1-5.

13. Sipe Lynn (2006) Understanding the workflow complexities of dealing with electronic resources. In: Current issues in collection development: Italian and global perspectives: Proc. Intl. Workshop on Collection Development. $18^{\text {th }}$ February 2005, Bologna. pp: 171-184.

14. Stoffle Caral J, Fore Janet and Allen Barbara (1999) Developing the new models for collection development. Haworth Press, New York pp:71.

15. Vohra Rajana (1999) Collection development and management in university libraries in the current electronic information environment. Laslic Bull. 48(4) 224-230.

16. William Bernard (2002) Truth and Truthfulness. University Press, Princeton.

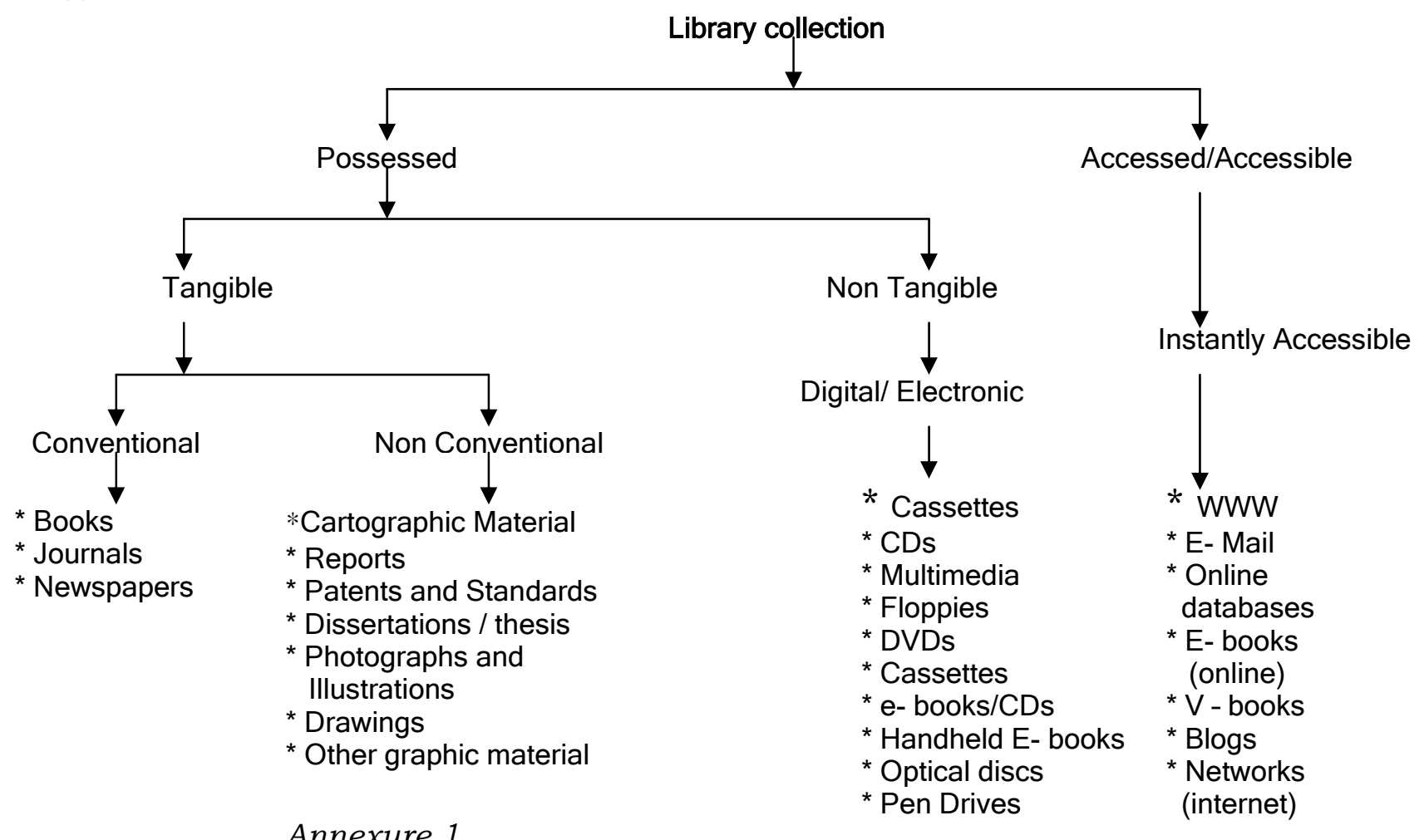

Sci. Technol. Edu. 